\title{
Effects of Reagent Concentration and Particle Size on Diffusion Rate of Mixed Ores with Rare Elements
}

\author{
X.Z. YANG AND L. ZHANG \\ School of Sciences, Changchun University, Changchun 130022, P.R. China \\ (Received July 23, 2012; in final form March 16, 2013)
}

The leaching reaction kinetics of weathered crust elution-deposited rare earth with mixed ammonium salts was studied. The influence of concentration of reagents and particle size of ore on leaching rate was investigated. The results showed that the diffusion process and leaching rate could be improved by increasing reagents concentration and decreasing leaching flowing rate and particle size. The leaching process could be explained with the shrinking core model, which could be controlled by the diffusion rate of reacting reagents in porous solid layer. The leaching rate obeyed the equation as $1-2 / 3 \eta-(1-\eta)^{2 / 3}=7.126 \times 10^{-4} C^{0.3038} R^{0.1942} t$.

DOI: $10.12693 /$ APhysPolA.124.66

PACS: 66.30.Fq, 91.65.Rg

\section{Introduction}

Weathered crust elution-deposited rare earth ore is China's unique rare earth mineral resource [1-3]. There are many advantages for ore which has widespread distribution rich reserves, low radioactivity, rich in middle and heavy rare earth, easily extracted rare earth, simple processing for leaching and a high quality of products, etc. The development and utilization of the ore in the world has significant influence, especially rare earth mineral resources were paid attention in our country these years. Therefore, high efficiency and comprehensive exploitation of weathered crust elution-deposited rare earth ore were intensively investigated over the past decade.

Leaching of the rare earth ore is liquid-solid multiphase reaction process, the most common reaction model has two kinds of integral scaled model and shrinking-core model. Mixed ammonium salts solution as leaching agent, the particle size of ore has little changed before and after leaching reaction, therefore, leaching process of rare earth ore is a common shrinking-core model. Leaching rate is connected with concentration, temperature, surface area of solid phase, etc. The leaching process can be controlled by outer diffusion, inner diffusion, chemical reaction $[4,5]$. The influence of concentration of reagents, particle size of ore on the leaching rate were investigated to achieve the aim of high RE concentration, low consumption of leaching reagent and high leaching rate.

\section{Experimental}

\subsection{Ore samples analysis}

Ore samples are mostly random and non-cemented sands, pale flesh red, containing clay minerals, quartz sand and rock-forming feldspar etc. which was obtained from Jiangxi province Dingnan. The content of clay minerals is about $40 \%-70 \%$, and $90 \%$ of rare earth ions are adsorbed in a state of kaolinite and mica. The chemical compositions of ore are listed in Table.
The main components of ore.

TABLE

\begin{tabular}{c|c|c|c|c|c|c}
\hline $\begin{array}{c}\text { Main } \\
\text { components }\end{array}$ & $\mathrm{REO}$ & $\mathrm{SiO}_{2}$ & $\mathrm{Al}_{2} \mathrm{O}_{3}$ & $\mathrm{Fe}_{2} \mathrm{O}_{3}$ & $\mathrm{CaO}$ & Others \\
\hline content [\%] & 0.1146 & 61.80 & 14.28 & 3.190 & 0.470 & 20.15
\end{tabular}

\subsection{Process and method}

Prior to the leaching experiments, the ore sample was sieved into +20 mesh, 20-60 mesh, 60-100 mesh, 100-140 mesh, +140 mesh five natural grain grades. And then, synthetic ore samples according to proportion of the natural grain grades, which were weighed into glass flask. Leaching agent taking a certain liquid-solid ratio and the flow velocity drops rare earth ore into consideration, then continuous leaching and collected leaching solution respectively. The $\mathrm{RE}^{3+}$ concentration was determined by EDTA titration method [6], measuring the volume of leaching reagent. The leaching process was evaluated by the RE leaching rate, which was calculated according to the following formula:

$$
\eta=\varepsilon / \varepsilon_{0},
$$

where $\varepsilon$ and $\varepsilon_{0}$ are the amount of leaching-out $\mathrm{RE}^{3+}$ and the total $\mathrm{RE}^{3+}$ content of sample ore, respectively.

\subsection{Leaching mechanism of rare earth}

The leaching process of the weathered crust elution-deposited rare earth ore is a kind of ion-exchange between the positive ions in the solution and the clay minerals $[7,8]$. The chemical reaction equation is as follows:

$$
\begin{gathered}
{\left[\mathrm{Al}_{4}\left(\mathrm{Si}_{4} \mathrm{O}_{10}\right)(\mathrm{OH})_{8}\right] m \mathrm{RE}_{(S)}^{3+}+3 \mathrm{nNH}_{4}^{+}(\mathrm{aq}) \Leftrightarrow} \\
{\left[\mathrm{Al}_{4}\left(\mathrm{Si}_{4} \mathrm{O}_{10}\right)(\mathrm{OH})_{8}\right] m\left(\mathrm{NH}_{4}^{+}\right)_{3 n(s)}+\mathrm{nRE}_{(\mathrm{aq})}^{3+} .}
\end{gathered}
$$

The weathered crust elution-deposited rare earth ore is composed of ore particles, the leaching process of ore is a typical liquid-solid heterogeneous reaction. The leaching process can be described by the shrinking-core model and subdivided into five steps as follows [9]:

- Diffusion of leaching reagent $\left(\mathrm{NH}_{4}^{+}\right)$through the 
film surrounding the particle to the surface of the clay minerals (outer diffusion);

- Penetration and diffusion of $\mathrm{NH}_{4}^{+}$to the surface of the un-reacted core (inner diffusion);

- Reaction of $\mathrm{RE}^{3+}$ with $\mathrm{NH}_{4}^{+}$(chemical reaction);

- Diffusion of the $\mathrm{RE}^{3+}$ exchanged through the remainder back to the exterior surface of the clay minerals (inner diffusion);

- Diffusion of the $\mathrm{RE}^{3+}$ exchanged through the exterior surface back into the solution of fluid (outer diffusion).

The kinetic control model of RE leaching process can be divided into four models $[10,11]$ :

1. Chemical reaction control: $1-(1-\eta)^{1 / 3}=k_{1} t$;

2. Diffusion through liquid film control: $1-(1-$ $\eta)^{1 / 3}=k_{1} t$

3. Diffusion through porous ore matrix control: $1-$ $\frac{2}{3} a-(1-a)^{2 / 3}=k_{3} t$

4. Mixed control: $1-(1-a)^{1 / 3}=\frac{k_{1} k_{2}}{k_{1}+k_{2}} \frac{C_{0} M}{r_{0} p}$,

where $k_{1}, k_{2}, k_{3}$ are constants for different control steps, respectively. $a, t, C_{0}, r_{0}, p$ and $M$ represent the rare earth leaching rate, leaching time, initial concentration of leaching reagent, initial radius of the ore particle, mole density of the ore particle and mass of the ore particle, respectively.

\section{Results and discussion}

According to the optimum process of mixed ammonium salts leaching rare earth ore experiment showed that the leaching rate of rare earth ore can reach up to $94.05 \%$ when $2.0 \% \quad \mathrm{NH}_{4} \mathrm{NO}_{3}$ and $\left(\mathrm{NH}_{4}\right)_{2} \mathrm{SO}_{4}$ quality ratio of $7: 3$, solid-liquid ratio of $0.5: 1$, flow rate of $0.5 \mathrm{~mL} / \mathrm{min}$. The rare earth leaching dynamics was researched on the basis of this process to find out the influence factors of leaching rate and control steps.

\subsection{Effect of leaching reagent concentration}

The initial average particle size of $0.2414 \mathrm{~mm}$ rare earth ore was leached by different concentration of mixed ammonium salts under the condition of $\mathrm{NH}_{4} \mathrm{NO}_{3}$ and $\left(\mathrm{NH}_{4}\right)_{2} \mathrm{SO}_{4}$ quality ratio of $7: 3$, solid-liquid ratio of $0.5: 1$, flow rate of $0.5 \mathrm{~mL} / \mathrm{min}$. The influence of different concentration of reagents on the leaching rate was investigated. According to the reaction system, the reaction rate is proportional to the concentration of the product, increasing the leaching agent concentration is conductive to the improvement of the leaching reaction rate, thereby increasing the rare earth leaching rate.

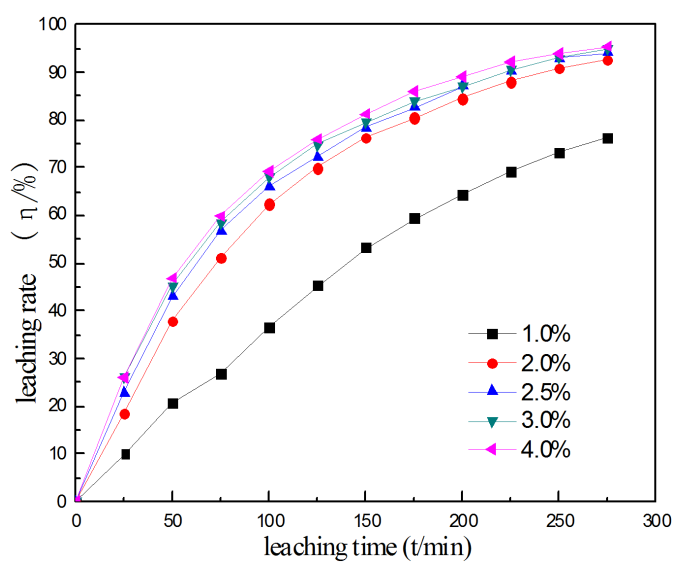

Fig. 1. Effect of concentration of reagents on rare earth leaching rate.

Figure 1 shows that the leaching rate of rare earth increases with initial concentration of ammonium salt increases, if the leaching agent concentration of $2.0 \%$ in 275 min rare earth leaching rate is $92.79 \%$, with the mass fraction of leaching agent increases, the unit volume of ammonium nitrate leaching agent rate increases, leading to the main leaching agent in a large number of $\mathrm{Al}^{3+}$ impurities leaching, some will cover the surface of the rare earth ore, hinder $\mathrm{RE}^{3+}$ leaching.

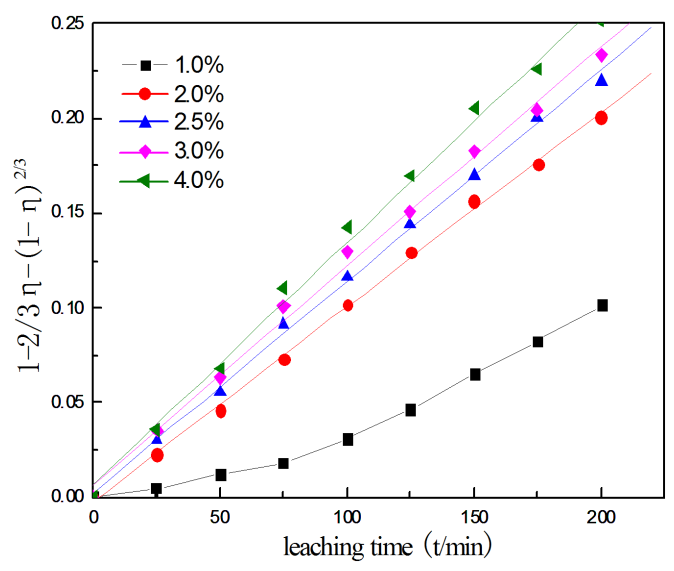

Fig. 2. Leaching kinetic data in different concentration of rare earth.

The date of rare earth leaching rate were substituted into the shrinking-core model in Fig. 2. When the mass fraction of leaching agent is greater than or equal to $2 \%$, satisfies the equation $1-2 / 3 \eta-(1-\eta)^{2 / 3}=k t$. Indicating that the leaching process step of rare earth ore is inner diffusion controlled, there can be used model equation

$$
1-2 / 3 \eta-(1-\eta)^{2 / 3}=k^{\prime} C^{a} R^{b} t,
$$

where $\eta$ - rare earth leaching rate [\%], $C$ - concentration of leaching reagent $[\mathrm{g} / \mathrm{L}], R$ - initial radius of the ore particle $[\mathrm{mm}], t$ - leaching time [min]. This equa- 
tion reflects the influence of leaching concentration and particle size of rare earth on the leaching rate.

Figure 2 shows different concentrations of $\mathrm{NH}_{4} \mathrm{NO}_{3}$ and $\left(\mathrm{NH}_{4}\right)_{2} \mathrm{SO}_{4}$ compound of rare earth leaching agent the apparent rate constant $k$ value, assuming $t$ had the apparent rate constant and is proportional to the power function of the concentration of leaching agent, that $\ln k=B+a \ln C$, least squares linear fit with slope requirements. Figure 3 shows a linear relationship between $\ln k$ and $\ln C$, and the apparent reaction order is 0.3038 , so $a=0.3038$.

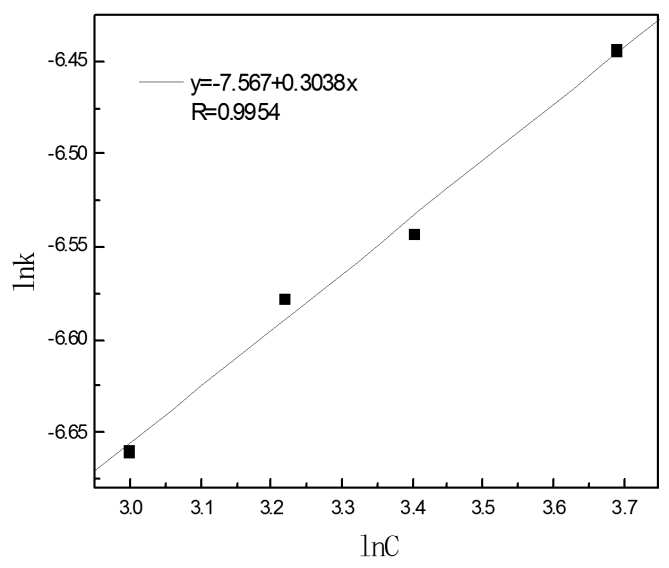

Fig. 3. Relation of $\ln C$ and $\ln k$.

\subsection{Effect of ore particle size}

Rare earth ore of the different particle size was leached by mixed ammonium salts under the condition of $2 \%$ $\mathrm{NH}_{4} \mathrm{NO}_{3}$ and $\left(\mathrm{NH}_{4}\right)_{2} \mathrm{SO}_{4}$ quality ratio of $7: 3$, solid-liquid ratio of $0.5: 1$, flow rate of $0.5 \mathrm{~mL} / \mathrm{min}$. The influence of different particle size on the leaching rate was investigated.

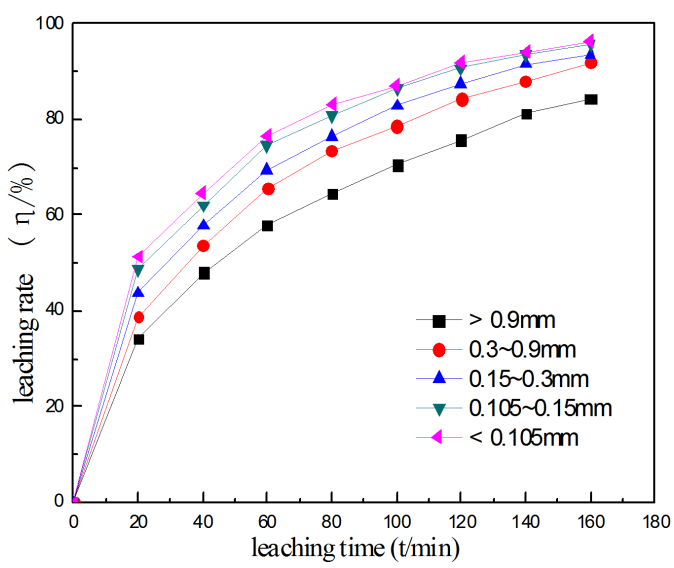

Fig. 4. Effect of particle size on rare earth leaching rate.

Figure 4 presents the effect of particle size on the rare earth leaching. It shows that the rare earth leaching rate of ore particles with a smaller size is greater, as shown in Fig. 5. It is known that the smaller the particle size, the more pore, at the same time shorten the length of pore, thereby reducing the resistance of inner diffusion and shorten spread time to the effect of speeding up the rare earth leaching. The leaching process could be explained with the shrinking core model according to ore particle size experiment.

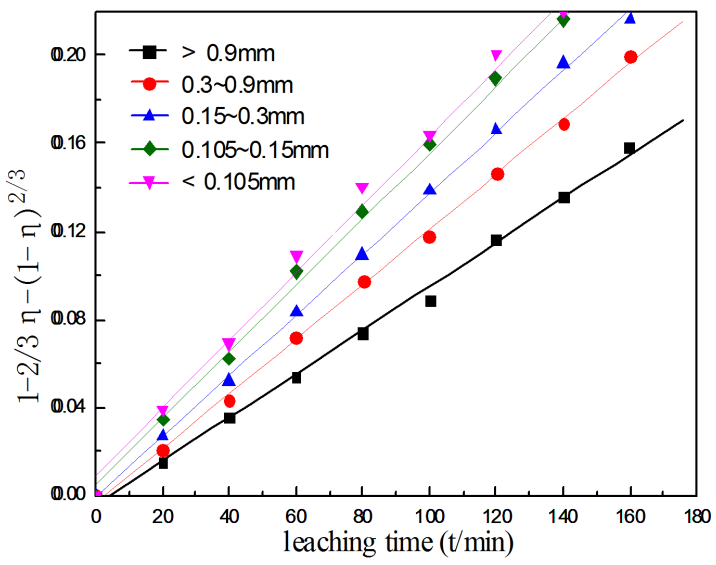

Fig. 5. Leaching kinetic data of rare earth in different particle size.

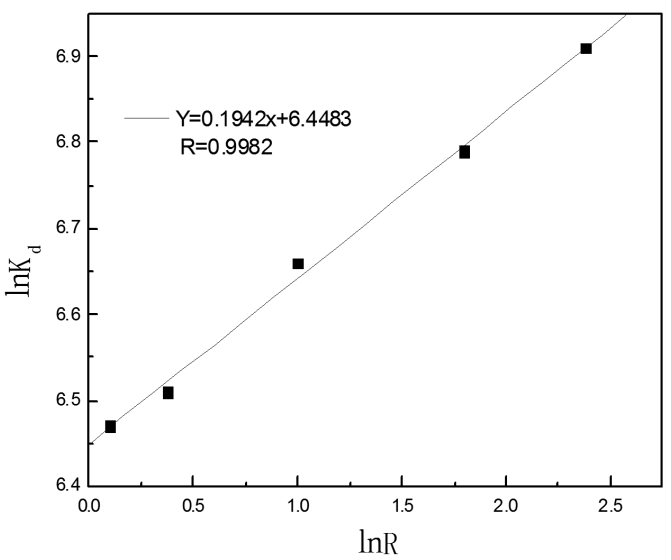

Fig. 6. Relation of $\ln k_{d}$ and $\ln R$.

As shown in Fig. 6, a good linearity exists between $\ln k_{d}$ and $\ln R$, the leaching process could be controlled by the diffusion rate of reacting reagents in porous solid layer furthermore, $\ln k_{d}=6.4483+0.1942 \ln R$, so $b=0.1942$.

$a$ and $b$ were presented in the equation of $1-2 / 3 \eta-$ $(1-\eta)^{2 / 3}=k^{\prime} C^{a} R^{b} t$, changing one factor, fixing others at the same time, so $k^{\prime}$ is $7.126 \times 10^{-4}$. Thereby the equation of mixed ammonium salts leaching rare earth ore is $1-2 / 3 \eta-(1-\eta)^{2 / 3}=7.126 \times 10^{-4} C^{0.3038} R^{0.1942} t$.

\section{Conclusions}

The leaching kinetics of weathered crust elution-deposited rare earth with mixed ammonium salts was 
investigated. The shrinking core model with inner diffusion control was used to describe the leaching process of rare earth. It was summarized as follows: the leaching rate increases with the increase of leaching reagent concentration and decrease of particle size. The kinetics of weathered crust elution-deposited rare earth leaching equation can be expressed as $1-2 / 3 \eta-(1-\eta)^{2 / 3}=$ $7.126 \times 10^{-4} C^{0.3038} R^{0.1942} t$.

\section{References}

[1] R. Chi, J. Tian, Weathered Crust Elution-Deposited Rare Earth Ores, Nova Science Publishers, Inc., New York 2008.

[2] R. Chi, Z. Guocai, Trans. Nonferrous Metal Soc. China 8, 693 (1998).

[3] R. Chi, J. Tian, J. Chin. Rare Earth Soc. 25, 641 (2007).
[4] T. Xunzhong, L. Maonan, Min. Res. Develop. 17, 1 (1997).

[5] M. Dingcheng, Metallurgical Kinetic Study, Central South University of Technology Publisher, Changsha 1987.

[6] F. Zhaoheng, Leaching, Metallurgical Industry Publishers, Beijing 2007.

[7] R. Chi, Z. Dai, Z. Oxus, Y. Wu, C. Wang, Trans. Nonferrous Met. Soc. China 16, 1421 (2006).

[8] H. Yao, X. OuYangKe, G. Rao, Jiangxi Sci. 23, 721 (2005).

[9] J. Tian, Y. Jingqun, Rare Metal 22, 330 (1996).

[10] J. Tian, L. Shengliang, Y. Jingqun, Eng. Chem. Metall. 16, 354 (1995).

[11] H.Y. Sohn, M.E. Wadsworth, Extraction Metallurgy Rate Process, Metallurgical Industry Publ., Beijing 1983. 